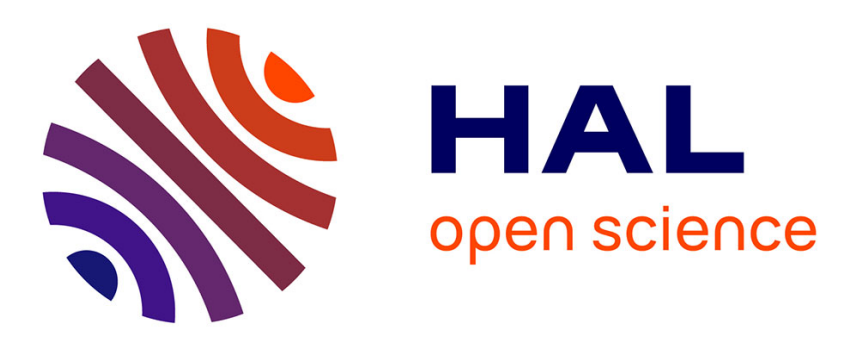

\title{
A new Strategy to Improve Drug Delivery to the Maxillary Sinuses: The Frequency Sweep Acoustic Airflow
}

Amira El Merhie, Laurent Navarro, Xavier Delavenne, Lara Leclerc, Jérémie Pourchez

\section{To cite this version:}

Amira El Merhie, Laurent Navarro, Xavier Delavenne, Lara Leclerc, Jérémie Pourchez. A new Strategy to Improve Drug Delivery to the Maxillary Sinuses: The Frequency Sweep Acoustic Airflow. Pharmaceutical Research, 2016, 33 (5), pp.1074-1084. 10.1007/s11095-015-1851-7 . hal-01319445

\section{HAL Id: hal-01319445 \\ https://hal.science/hal-01319445}

Submitted on 20 May 2016

HAL is a multi-disciplinary open access archive for the deposit and dissemination of scientific research documents, whether they are published or not. The documents may come from teaching and research institutions in France or abroad, or from public or private research centers.
L'archive ouverte pluridisciplinaire HAL, est destinée au dépôt et à la diffusion de documents scientifiques de niveau recherche, publiés ou non, émanant des établissements d'enseignement et de recherche français ou étrangers, des laboratoires publics ou privés. 
A new strategy to improve drug delivery to the maxillary sinuses: the frequency sweep acoustic airflow

Amira El Merhie ${ }^{a}$, Laurent Navarro ${ }^{a}$, Xavier Delavenne ${ }^{b}$, Lara Leclerc ${ }^{a}$, Jérémie Pourchez .

a Ecole Nationale Supérieure des Mines, CIS-EMSE, EA 4624 - LINA, SFR FED 4166 IFRESIS, F-42023 Saint-Etienne, France

b Laboratoire de Pharmacologie - Toxicologie, CHU de Saint-Etienne, F42055 Saint-Etienne, France

Suggested running head: Frequency sweep acoustic airflow for improved drug delivery

\section{Contact information}

Corresponding author: Lara Leclerc

Laboratoire Interdisciplinaire d'étude des Nanoparticules Aérosolisées (LINA - EA 4624)

Ecole Nationale Supérieure des Mines de Saint-Etienne

Centre Ingénierie et Santé

10 rue de la Marandière - 42270 Saint-Priest en Jarez

Email: Leclerc@emse.fr 


\begin{abstract}
Purpose Enhancement of intra-nasal sinus drug deposition involves nebulization of a drug superimposed by the acoustic airflow characterized by a specific frequency. We investigated the impact of fixed frequency versus frequency sweep acoustic airflow on the improvement of aerosolized drug penetration into the maxillary sinuses.
\end{abstract}

Methods Fixed frequency and frequency sweep acoustic airflow were generated using a prototype of variable frequency nebulizing system, and their effect on the intra-nasal sinus aerosol deposition in a 'nasal replica', a transparent, water-resistant, non-porous resin replica of the human plastinated cast created using a stereolithography technique, was tested. Sodium fluoride and gentamicin were chosen as markers. In addition to this, the effect of sweep cycle and intensity variation was also studied.

Results Studies performed using fixed frequency acoustic airflow showed that each of the maxillary sinuses of the 'nasal replica' required specific frequency for the optimal intra-nasal sinus aerosol deposition; depending on the ostia of the left and right maxillary sinuses which are different. Intra-nasal sinus drug deposition experiments under the effect of the frequency sweep acoustic airflow showed an optimal aerosol deposition into both maxillary sinus of the "nasal replica'. Studies on the effect of the duration of the sweep cycle showed that the shorter the cycle the better the deposition.

Conclusion Our study demonstrates the benefit of frequency sweep acoustic airflow on the drug deposition into maxillary sinuses of the 'nasal replica' characterized by ostia of different geometry. However, the delivery rates of the 'nasal replica' cannot be directly applied to real human chronic rhinosinusitis condition; further in vivo studies have to be conducted. 
KEY WORDS: Frequency sweep acoustic airflow, fixed frequency, sweep cycle, intra-nasal sinus deposition.

\section{List of Abbreviations}

CRS: Chronic Rhinosinusitis

FESS: Functional Endoscopic Sinus Surgery

MS: Maxillary Sinuses

NaF: Sodium Fluoride

LC-MS/MS: Liquid Chromatography-Tandem Mass Spectrometry

LMS: Left Maxillary Sinus

RMS: Right Maxillary Sinus 


\section{Introduction}

Chronic rhinosinusitis (CRS) is a common disorder characterized by mucosal inflammation of the nose and paranasal sinuses with sinonasal symptoms persisting for greater than 12 weeks (1). Sinonasal symptoms involve nasal blockage, obstruction, congestion or nasal discharge (anterior or posterior nasal drip) (2). The nose and paranasal sinuses constitute a collection of air filled spaces within the anterior skull. The paranasal sinuses communicate with the nasal cavity through small apertures, known as maxillary ostia $(3,4)$. The osteomeatal complex, composed of maxillary ostia and four other structures, plays a major role in clearing of the paranasal sinuses with mucus moving through these small orifices (1). Blockage of sinus drainage through infection of the nasal mucosa or impaired mucociliary clearance produces a favorable environment for sinusitis in which pathogens may proliferate. CRS is a significant and increasing health problem which results in a large financial burden on society $(5,6)$. The etiology of CRS is incompletely understood; therefore, the management of this complex disease remains a challenge. Various systemic therapeutic agents are commonly employed. However, long term use of systemic agents, such as corticosteroids and antibiotics, over prolonged periods results in adverse effects, drug interactions, and antimicrobial resistance. Hence, functional endoscopic sinus surgery (FESS) plays a vital role in the treatment process. There are, however, several negative factors that are still present after surgery, including potential offending bacteria, fungi, viruses, and the patients' immunologic responses. These factors and others cause many patients to have frequent, recurrent acute infections compounding their chronic sinusitis. To avoid this, studies have been redirected towards determining better treatments with fewer implications. The development of topical therapy delivered directly to the sinonasal cavity has created an alternative treatment strategy preventing sinus surgery or at least delaying the need for sinus 
surgery. Antibiotics are the most commonly prescribed medication for CRS due to its recognized efficacy on rhinosinusitis associated bacteria (7). Nebulization is a widely used means of drug delivery to the upper and lower airways as it possesses an advantage over classic means by directly reaching the target area and enhancing local nebulized drug deposition (8). The effectiveness of nasal nebulization to target maxillary sinuses has been previously demonstrated in several studies $(9,10,11,12,13)$. Nebulizing devices should enable deposition over the entire nasal cavity surface, including medial meatus, unlike nasal sprays. Nebulizers with additional acoustic airflow function are recommended for the treatment of CRS. These medical devices are enabled to generate acoustic airflows that induce acoustic hyper pressure in the ostium, displacing the air and aerosol towards the maxillary sinuses thus allowing sinus ventilation $(8,15,16,10)$. The efficacy of superposition of the acoustic airflow on the nebulized drug has been demonstrated in previous studies. For example, Mainz et al. in his pilot study in cystic fibrosis patients with upper airway Pseudomonas aeruginosa colonization has showed that sinonasal inhalation of antibiotics applied as vibrating aerosols gave promise as a non-invasive method for the treatment of upper airway diseases (16). Recently, we have studied the gentamicin deposition in the maxillary sinuses under the effect of high frequency $(\mathrm{f} \geq 100 \mathrm{~Hz})$ and low frequency $(\mathrm{f} \leq 45 \mathrm{~Hz}$ ) acoustic airflow. We demonstrated the benefit of different modes of vibrating acoustic airflow for maxillary sinus ventilation and intra-sinus drug deposition, and that the degree of gentamicin deposition varies as a function of frequency of the acoustic airflow and the geometry of the ostia (17). Hence, depending on the degree of obstruction of the ostia in CRS patients, the concentration of drug penetrated to the sinuses varies. Therefore, we can make a hypothesis that using patient specific acoustic airflow (depending on the ostia geometry); improved treatment of CRS could be achieved in the future. Nowadays, commercial medical 
nebulizing devices are being characterized by an acoustic airflow of fixed frequency. A new strategy capable of addressing different morphology of maxillary ostia is being sought to find a universal solution for the majority of CRS patients; volume and dimensions of maxillary sinuses and their ostia change throughout the progression of CRS. This study aims at investigating the impact of frequency sweep acoustic airflow on the enhancement of the aerosol deposition into the maxillary sinuses in a well-characterized nasal replica. The main purpose of this work was to demonstrate the benefit of a new strategy, i.e. the frequency sweep acoustic airflow on the enhanced drug deposition, whatever the ostium morphology, compared to actual strategy consisting of acoustic airflow of fixed frequency. 


\section{Materials and Methods}

\subsection{Anatomic nasal replica}

In this study, a nasal replica of a human plastinated cast was used. The plastination technique, the methods of obtaining the human plastinated cast, its anatomic characteristics and the advantages it provides to the aerosol deposition experiments were described in previous studies $(18,13)$. CT scan images of the human plastinated cast were numerically analyzed to obtain the dimensions of ostia and the volume of maxillary sinuses (MS); thus allowing the calculation of the resonance frequency of the MS using Helmholtz resonator theory (19).

A nasal, transparent, water-resistant, non-porous resin replica of the human plastinated cast, created using a stereolithography technique (13), was used to perform sodium fluoride (NaF) aerosol and then gentamicin aerosol deposition experiments. Anatomical and aerodynamic reproducibility between the nasal replica and its human plastinated cast were confirmed after performing endoscopy and CT scans (13). The left maxillary ostium is characterized by being short and broad while the right maxillary ostium is long and narrow. The advantage of using the nasal replica over the human plastinated cast was previously described (20).

\subsection{Reconstruction of $3 D$ image}

Analysis of the images obtained from cranially scanning the human plastinated head using CT scanner (Lightspeed VCT, GE Healthcare) of $0.2 \mathrm{~mm}$ slice spacing was performed. The images were analyzed to determine the volume of maxillary sinuses in addition to the geometric dimensions of maxillary ostia (length and diameter). Having determined these parameters, it was possible to calculate the resonance frequency of each MS; therefore comparing the numerically obtained values with the experimental ones. Steps of 
reconstruction involved manual segmentation of each slice using polygonal approximation (Fig. 1). The segmentation process was performed on the total number of slices. After treating each slice with the polygon active tool, the total number of pixels of the total segmented volume was determined, and the volume of each maxillary sinus was calculated. This procedure was performed for each sinus separately. That was the first part of numerical analysis.

The second part consisted of determining dimensions of maxillary ostia. Segmentation of the ostia was carried out following the same steps described above. After the selection of the required regions representing the ostia, to be able to determine exact dimensions of these ostia, selected regions were used to generate $3 \mathrm{D}$ volumetric mesh using the mesh generation and processing toolbox, iso2mesh. The mesh was viewed using the MeshLab software and the required dimensions were measured. Finally, applying the Helmholtz resonator formula $\left(f=\frac{c}{2 \pi} \sqrt{A / V L}\right)(17)$, the resonance frequency of the left and right maxillary sinuses was calculated.

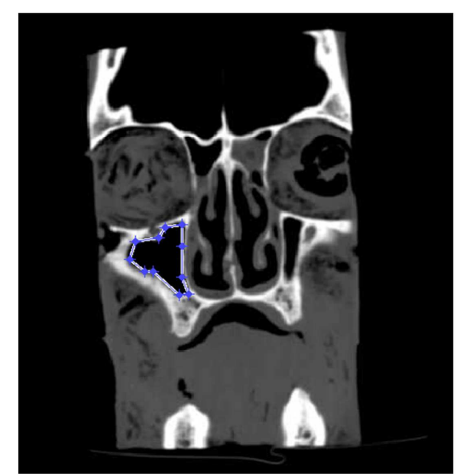

Figure 1 Manual segmentation of the region representing MS of each slice of CT scan images of human plastinated cast using polygonal approximation. 


\subsection{Medical nebulizing systems}

Two medical nebulizing systems were used in this study. The first commercial medical device used was the ATOMISOR NL11 jet nebulizer connected to the AOHBOX compressor (DTF Medical, Saint-Etienne, France). The jet nebulizer was connected to the nasal plug (C28, DTF Medical, Saint-Etienne, France) that ensured the connection with the nostrils of the nasal replica. This device was operated in its classic mode, i.e. producing the aerosol without superimposing its acoustic airflow. The output rate of the device is $0.2 \mathrm{ml} / \mathrm{min}$ and its MMAD of aerosol particle size is $2.75 \pm 0.2 \mu \mathrm{m}$.

The second commercial medical device was the PARI SINUS jet nebulizer associated with a PARI SINUS compressor (Pari GmbH, Starnberg, Germany). It was also used for the production of non-acoustic airflow nebulization only, by disconnecting the vent tubing from the acoustic airflow output of the compressor. The nebulizer was coupled to the same nasal plug as in the experiments with the ATOMISOR NL11. Thus, the PARI SINUS device was not used according to producer specifications (i.e. one nostril in, the other out). In fact, as the aim of this work was the impact of acoustic airflow on intra-sinus drug delivery; same experimental protocol of aerosol administration to the nasal fossa for both nebulizing devices was required to avoid biases due to the impact of the nasal plug. As a result, we must underline that the results of intra-sinus drug deposition for the PARI SINUS device cannot be representative of data obtained in vivo according to the producer specifications (17). The output rate of this PARI SINUS device is $0.22 \mathrm{ml} / \mathrm{min}$ and its MMAD is equal to $3.3 \pm 0.1$ $\mu \mathrm{m}$. 
Both the PARI SINUS and the DTF medical nebulizing systems were chosen to be used in our study as they have appeared in citations of numerous studies performed in France and worldwide $(20,21,11,15)$.

\subsection{Sweep Acoustic airflow set-up}

The sweep acoustic airflow set-up acts as a prototype of variable frequency nebulizing system. Its role in our study was to generate acoustic airflow of single and fixed frequency in the $50-800 \mathrm{~Hz}$ range as well as frequency sweep modes. It consists of a vibration exciter TIRAvib S 50009 (TIRA GmbH, Schalkau, Germany) and a power amplifier TIRA BAA 60 (TIRA GmbH, Germany). The vibration exciter is an electrodynamic transducer with a wide frequency range of 2 to $20 \mathrm{kHz}$, and it is supplied with a sinus wave signal driven by a power amplifier. For a complete operation of the system, a computer with a soundcard was used as a signal generator. Computer was connected to the power amplifier which was connected to the vibration exciter. Vibration exciter was producing an acoustic airflow delivered to the nebulizer via vent tubing (Fig. 2).

\subsection{Acoustic airflow nebulization}

In the first part of experiments, nebulization with an acoustic airflow characterized by a single and fixed frequency values was tested. We tested several frequency values: $50 \mathrm{~Hz}, 100 \mathrm{~Hz}$, $200 \mathrm{~Hz}, 300 \mathrm{~Hz}, 400 \mathrm{~Hz}, 500 \mathrm{~Hz}, 600 \mathrm{~Hz}, 700 \mathrm{~Hz}$ and $800 \mathrm{~Hz}(\mathrm{n}=6)$.

In the second part of experiments, we tested the frequency sweep acoustic airflow nebulization. Frequency sweep acoustic airflow is characterized by a range of frequency values repeated over a certain sweep cycle. We tested three frequency ranges; 45- $500 \mathrm{~Hz}, 45-$ 
$800 \mathrm{~Hz}$ and 100- $500 \mathrm{~Hz}$ over different sweep cycles (n=6). The effect of intensity of the acoustic airflow on the intra-sinus aerosol deposition was also tested.

Intensity of the acoustic airflow was measured using a C-weighted sound level meter (EXTECH Instruments, USA) used for the measurement of the maximum sound pressure level. It was positioned at the output of the NL11 nebulizer to measure the intensity of the acoustic airflow coming out of it. Variation in the level of intensity was induced using the power amplifier TIRA described in the previous section. Intensity level of the acoustic airflow produced by the DTF nebulizing system was also measured. Two intensity levels were tested, $128 \mathrm{~dB}$ acoustic airflow and $120 \mathrm{~dB}$ acoustic airflow, denoted respectively "high intensity" and "low intensity".

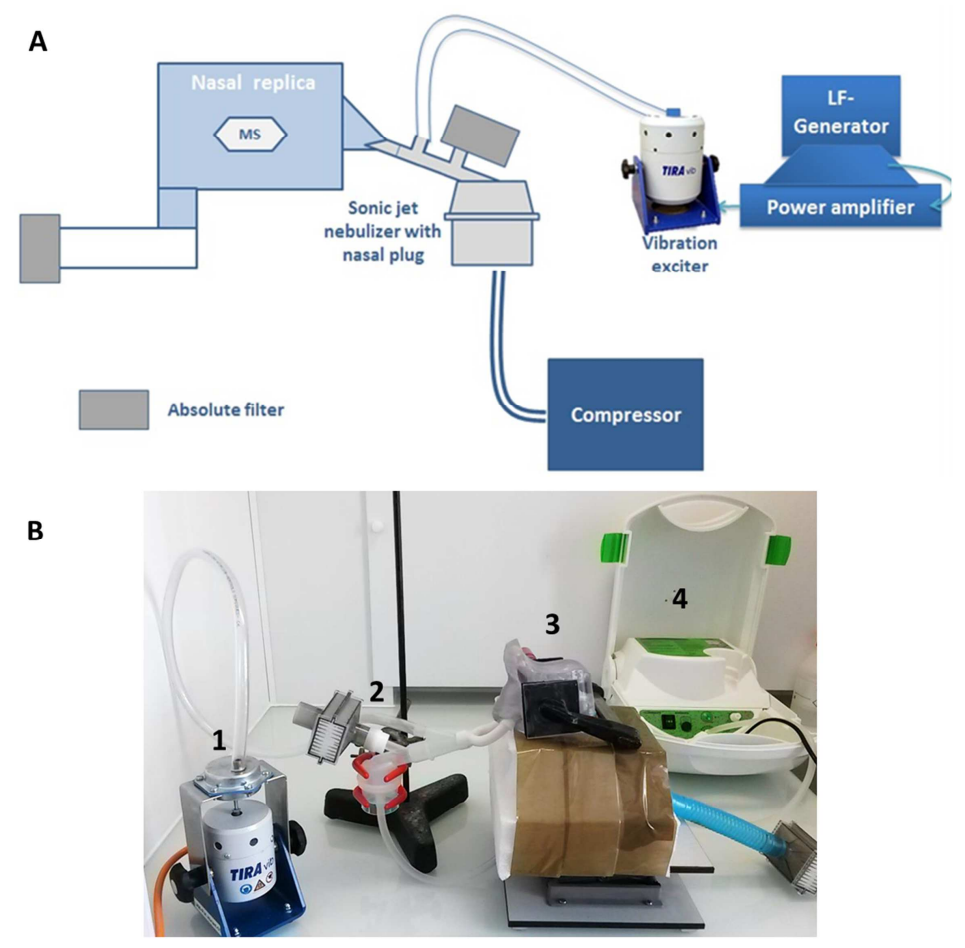

Figure 2 (a) Experimental design of frequency sweep acoustic airflow intra-sinus aerosol deposition study. (b) Experimental setup of frequency sweep acoustic airflow intra-sinus aerosol deposition study. (1) Vibration exciter (2) Nebulizer (3) Nasal replica (4) AOHBOX compressor. 


\subsection{Aerosol deposition into the maxillary sinuses}

Aerosol penetration into the maxillary sinuses under the effect of acoustic airflow characterized by a fixed frequency and then by a frequency sweep, was studied. This experimental work was divided into two major parts.

The first part involved the use of $\mathrm{NaF}, 2.5 \%(\mathrm{M} / \mathrm{V})$ as a chemical marker according to European standard procedure (NF EN 13544-1). Nebulizer NL11 was filled with $4 \mathrm{ml}$ of NaF and the nebulization using the DTF nebulizing system was performed (Fig. 2 (A), Fig. 2 (B)). The maxillary sinuses of the nasal replica were hermetically sealed during the experiments. All nebulization procedures lasted 10 minutes. At the end of each nebulization, the plates sealing the sinuses were then removed and the maxillary sinuses were flushed by syringe containing $5 \mathrm{ml}$ of distilled water. Each sinus was flushed a couple of times using the same distilled water. The region close to the maxillary ostium was never flushed (23). After every rinsing procedure, the nasal replica was removed from the setup and copiously washed with distilled water and dried with pulsed air. To verify the efficiency of model washing, distilled water nebulization experiments were randomly performed throughout the experiments by filling the nebulizers with $4 \mathrm{ml}$ of distilled water instead of $\mathrm{NaF}$.

The concentration of deposited $\mathrm{NaF}$ aerosol into MS was measured using the perfectIon Fluoride Electrode (METTLER TOLEDO, Switzerland) and the ion meter (METTLER TOLEDO, Switzerland) by adding $250 \mu \mathrm{L}$ of TISAB IV solution (Sigma-Aldrich, Germany) to every rinse liquid, according to the European standard procedure (NF EN 13544-1).

The second part of the experimental work involved the use of gentamicin (GENTAMICINE PANPHARMA $160 \mathrm{mg}-2 \mathrm{ml} ; 80 \mathrm{mg} / \mathrm{ml}$ ) as a marker. These experiments were performed as a final part of the study to verify, using a drug, the benefits of the tested acoustic airflow 
initially obtained using $\mathrm{NaF}$. The procedure involved filling the nebulizers with $4 \mathrm{ml}$ of a gentamicin solution operating at a flow rate of 8 L.min-1. The nasal replica was connected to a $15 \mathrm{~cm}$ long tube simulating the trachea equipped with an absolute filter. Nebulization lasted 10 minutes. After each nebulization, the plates closing the sinuses were then removed and the maxillary sinuses were flushed four times by syringe containing $1 \mathrm{ml}$ of distilled water. The complete experimental setup and the rinsing procedure were described in detail in the previous study (10). Gentamicin concentrations in samples were quantified by liquid chromatography- tandem mass spectrometry (LC-MS/MS).

\subsection{Statistical analysis}

Data of NaF concentration deposited into the maxillary sinuses was analyzed using Prism 5.0 software (GraphPad, SanDiego, CA). Graphs were plotted and significance $* * *(\mathrm{P}<0.001)$ and ** $(\mathrm{P}<0.01)$ was established by two-way ANOVA test $(\mathrm{p}<0.05)$ for both $\mathrm{NaF}$ and gentamicin deposition study. 


\section{Results}

\subsection{Reconstruction of 3D image; resonance frequency of LMS and RMS}

Images obtained from CT scanning of the human plastinated cast were numerically analyzed to determine the resonance frequency values of LMS and RMS. For the LMS, a volume of 10 $\mathrm{ml}$ was calculated. The diameter and length of its ostium were found to be equal to $7.2 \pm 0.4$ $\mathrm{mm}$ and $10.7 \pm 0.3 \mathrm{~mm}$ respectively. As for the RMS, a volume of $14 \mathrm{ml}$ was calculated and the diameter and length of its ostium were found to be $4.3 \pm 0.3 \mathrm{~mm}$ and $9.8 \pm 0.2 \mathrm{~mm}$ respectively. Therefore, by applying the Helmholtz resonator theory (17) where the maxillary sinus is compared with a sphere and the maxillary ostium is approximated as a cylindrical tube, the resonance frequency of the LMS of the nasal replica is $336 \pm 15 \mathrm{~Hz}$ and the resonance frequency of the RMS is $177 \pm 10 \mathrm{~Hz}$.

\subsection{Aerosol deposition into the maxillary sinuses using NaF as a chemical marker}

\subsubsection{Acoustic airflow with a fixed frequency}

Aerosol deposition into the maxillary sinuses was studied under the effect of acoustic airflow characterized by a fixed frequency. Each time an acoustic airflow was characterized by a certain single frequency value and superimposed on the nebulized chemical marker (i.e. NaF); then the concentration of the deposited NaF into the MS was measured.

As can be observed in fig. 3 (A), the high deposition of $\mathrm{NaF}$ aerosol into the RMS was reached when the acoustic airflow was characterized by either of the following frequencies: $150 \mathrm{~Hz}, 200 \mathrm{~Hz}$ and $300 \mathrm{~Hz}$. These three frequency values correspond to the maximum RMS deposition when compared to the rest frequency values studied. The effect of superposition of acoustic airflow characterized by one of the $500 \mathrm{~Hz}, 600 \mathrm{~Hz}, 700 \mathrm{~Hz}$, or $800 \mathrm{~Hz}$ frequencies is 
negligible. When the deposition results were tested for the statistical significance, it was found that the $150 \mathrm{~Hz}$ and the $200 \mathrm{~Hz}$ acoustic airflow superimposed on the nebulizer has increased the $\mathrm{NaF}$ deposition by 4-fold when compared with the $\mathrm{NaF}$ deposition in the absence of superposition of any acoustic airflow. The $300 \mathrm{~Hz}$ acoustic airflow has increased the NaF deposition by around 4.5 fold. The deposition under the effect of $400 \mathrm{~Hz}$ acoustic airflow was also significant but relatively less than the one obtained under the effect of $150 \mathrm{~Hz}, 200 \mathrm{~Hz}$ and $300 \mathrm{~Hz}$.

With respect to the intra-sinus NaF aerosol deposition into the LMS, the obtained results are shown on (Fig. 3 (B)). The high deposition of NaF solution into the LMS was reached when the acoustic airflow was characterized by either of the following frequencies: $150 \mathrm{~Hz}, 200 \mathrm{~Hz}$, $400 \mathrm{~Hz}$ and $500 \mathrm{~Hz}$. These four frequency values correspond to the maximum LMS deposition when compared with the deposition under the effect of the rest frequency values in this study. The deposition obtained under the effect of either $300 \mathrm{~Hz}$ or $600 \mathrm{~Hz}$ acoustic airflow is relatively high when compared with the nebulization performed without the superposition of acoustic airflow; however, it is smaller when compared with the four previously mentioned frequency values. The effect of superposition of acoustic airflow characterized by the $50 \mathrm{~Hz}$, $100 \mathrm{~Hz}, 700 \mathrm{~Hz}$ or $800 \mathrm{~Hz}$ frequency is negligible. When these results were tested for the statistical significance, it was observed that the $150 \mathrm{~Hz}$ or the $200 \mathrm{~Hz}$ acoustic airflow superimposed on the nebulizer has increased the NaF deposition by 4-fold when compared with the NaF deposition under in the absence of acoustic airflow superposition. The $300 \mathrm{~Hz}$ acoustic airflow has increased the $\mathrm{NaF}$ deposition by around 4.5 fold. The deposition under the effect of $400 \mathrm{~Hz}$ acoustic airflow was also significant but relatively less than the one obtained under the effect of $150 \mathrm{~Hz}, 200 \mathrm{~Hz}$ and $300 \mathrm{~Hz}$. 


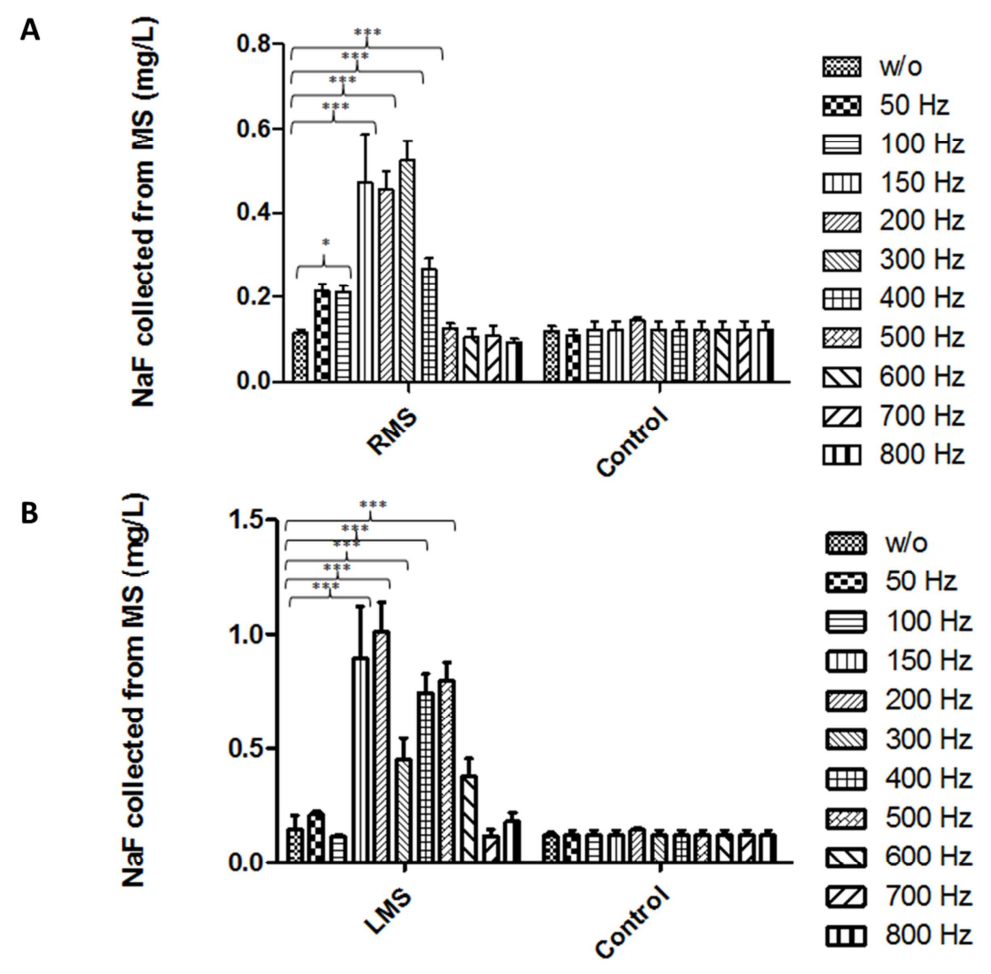

Figure 3 (a)-(b) impact of ( $50 \mathrm{~Hz}, 100 \mathrm{~Hz}, 150 \mathrm{~Hz}, 200 \mathrm{~Hz}, 300 \mathrm{~Hz}, 400 \mathrm{~Hz}, 500 \mathrm{~Hz}, 600 \mathrm{~Hz}, 700 \mathrm{~Hz}$ and $800 \mathrm{~Hz})$ acoustic airflow on nebulized $\mathrm{NaF}$ collected in the right and left maxillary sinuses respectively (in $\mathrm{mg} / \mathrm{L})(\mathrm{n}=6$, mean $\pm \mathrm{SEM}, *(\mathrm{P}<0.05), * * *(\mathrm{P}<0.0001)$ for RMS and $* * *(\mathrm{P}<0.001)$ for LMS $)$.

\subsubsection{Acoustic airflow characterized by a frequency sweep}

Aerosol deposition into the maxillary sinuses was studied under the effect of acoustic airflow characterized by a frequency sweep of sweep cycle duration equal to $0.3 \mathrm{~s}$. Three frequency ranges were tested $(50-500 \mathrm{~Hz}, 100-500 \mathrm{~Hz}$, and 50-800 Hz) and deposition results were compared for the selection of the optimum range corresponding to the maximum deposition of NaF into both maxillary sinuses of our model (Fig. 4 (A)). As for the right maxillary sinus, there is no difference observed in the deposited quantity of $\mathrm{NaF}$ between the three ranges. With respect to the left maxillary sinus, the optimum deposition was attained by superimposing the acoustic airflow characterized by the $100-500 \mathrm{~Hz}$ frequency sweep range. 
After selection of the frequency sweep range that led to the maximum NaF deposition into both MS of our nasal replica, the effect of the frequency sweep cycle on the intra-sinus aerosol deposition was tested. Three cycles were tested: $0.3 \mathrm{~s}, 3 \mathrm{~s}$, and $30 \mathrm{~s}$ (Fig. 4 (B)).

It can be observed that the longer the sweep cycle, the less the $\mathrm{NaF}$ deposition into the maxillary sinuses. Hence, sweep cycle of 0.3 seconds results in the efficient deposition of the aerosolized NaF into the maxillary sinuses.

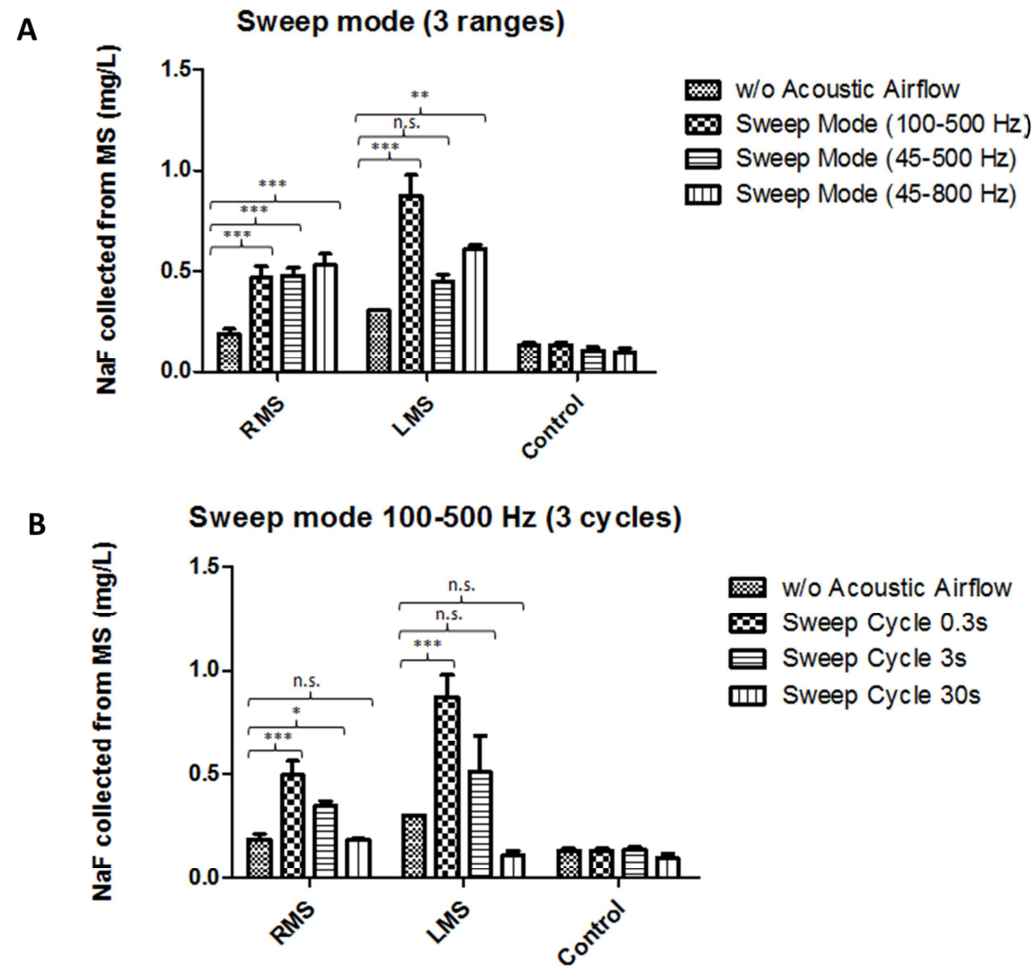

Figure 4 (a) Impact of three ranges of frequency sweep acoustic airflow of 0.3 s sweep cycle on the concentration (in $\mathrm{mg} / \mathrm{L}$ ) of $\mathrm{NaF}$ collected from the MS $(\mathrm{n}=6$, mean $\pm \mathrm{SEM}$, $* *(\mathrm{P}<0.01), * * *(\mathrm{P}<0.001))$. (b) Impact of sweep cycle on the concentration (in $\mathrm{mg} / \mathrm{L})$ of $\mathrm{NaF}$ deposited in the MS ( $\mathrm{n}=6$, mean $\pm \mathrm{SEM}, *(\mathrm{P}<0.05), * * *(\mathrm{P}<0.001))$.

Effect of intensity of the acoustic airflow on the intra-sinus aerosol deposition was also studied. Acoustic airflow characterized by a frequency sweep range of $100-500 \mathrm{~Hz}$ of $0.3 \mathrm{~s}$ sweep cycle was involved in this part of the study. The effect of high intensity acoustic airflow of $128 \mathrm{~dB}$ and the low intensity acoustic airflow of $120 \mathrm{~dB}$ was tested on the RMS and 
LMS separately (Fig. 5 (A), Fig. 5 (B)); a difference of $8 \mathrm{~dB}$ is high as the difference in decibels between the intensity levels is measured using logarithmic scale. It is clear from the figures that there is no significant effect of acoustic airflow intensity on the intra-sinus aerosol deposition.

A

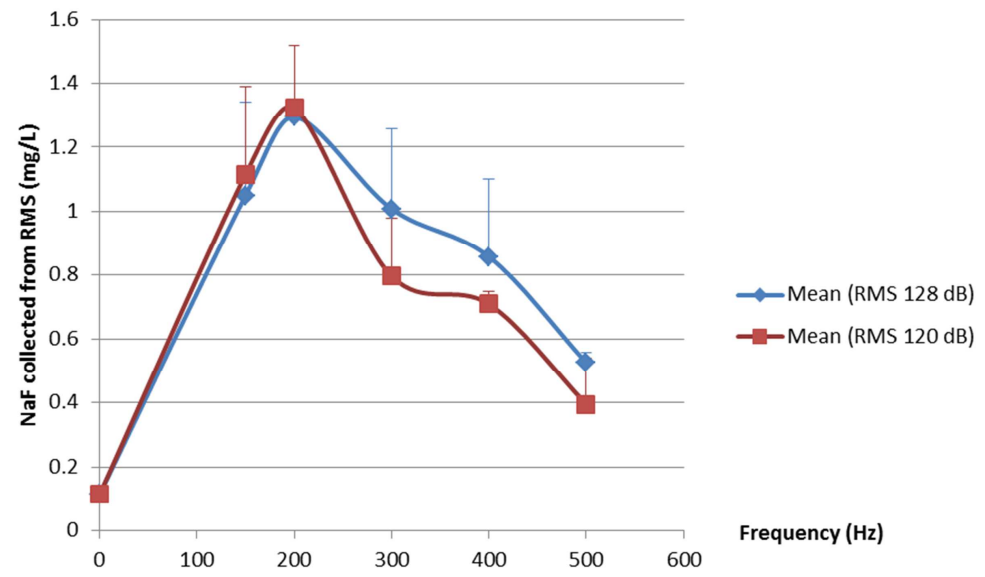

B

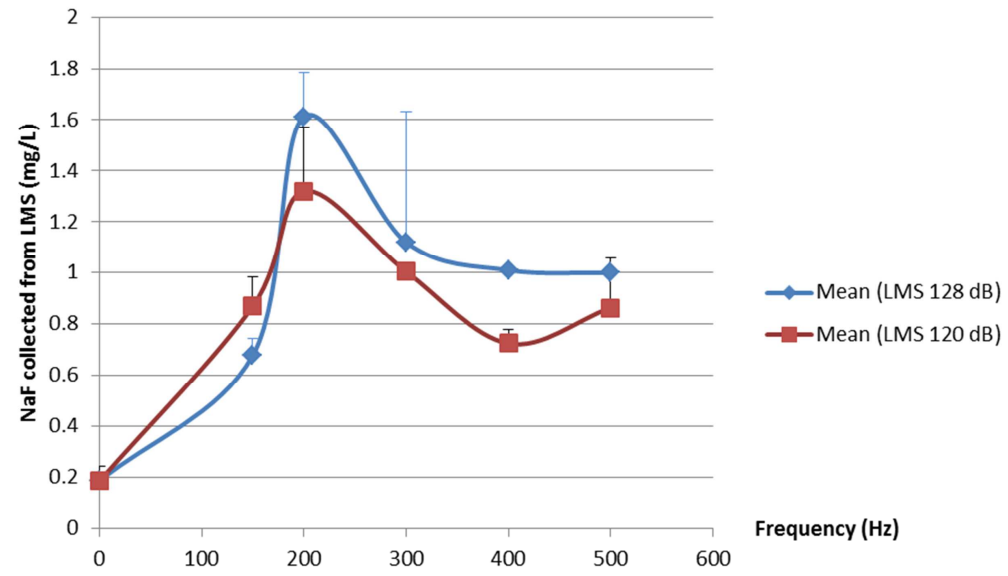

Figure 5 (a)-(b) effect of high intensity versus low intensity acoustic airflow on aerosol deposition into the right and left maxillary sinuses respectively. 
3.3 Aerosol experiments using gentamicin to assess the benefit of acoustic airflow on the intra-sinus drug deposition

Impact of sweep mode acoustic airflow on intra-sinus gentamicin deposition was tested using the AOHBOX compressor and the PARI SINUS compressor. Each of the compressors was coupled to its specific nebulizer. The acoustic airflow was characterized by a $100-500 \mathrm{~Hz}$ frequency sweep range of $0.3 \mathrm{~s}$ sweep cycle. Obtained deposition results were compared with the deposition results of our previous study (17). The obtained results clearly demonstrate that (Fig. 6):

- The frequency sweep mode acoustic airflow led to the enhanced gentamicin deposition into both maxillary sinuses when compared with the impact of vibrating acoustic airflow supplied by both nebulizing systems.

- With respect to the frequency sweep mode superimposed on the aerosol generated by the AOHBOX compressor through the NL11SN nebulizer (i.e. the commercial device), the drug deposition into the RMS was increased by 3-fold when compared with the effect of acoustic airflow. As for the LMS, the deposited drug quantity was comparable under the effect of either modes of acoustic airflow.

- With respect to the frequency sweep mode superimposed on the aerosol generated by the PARI SINUS jet nebulizer (i.e. the commercial device), the drug deposition into the RMS was increased by 2 -fold when compared with the effect of acoustic airflow. As for the LMS, the deposited drug quantity has increased by 1.5 -fold when comparing the effect of frequency sweep acoustic airflow with the acoustic airflow. 
A

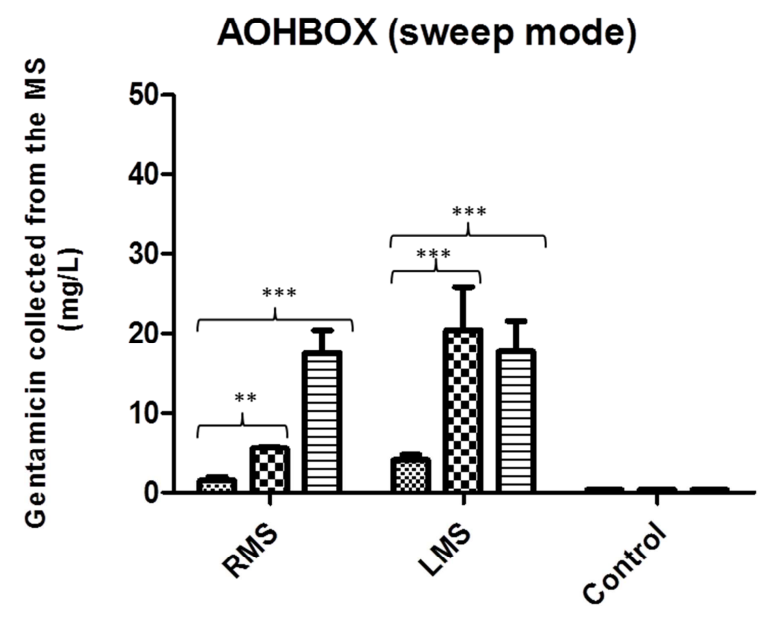

B

PARI SINUS (sweep mode)

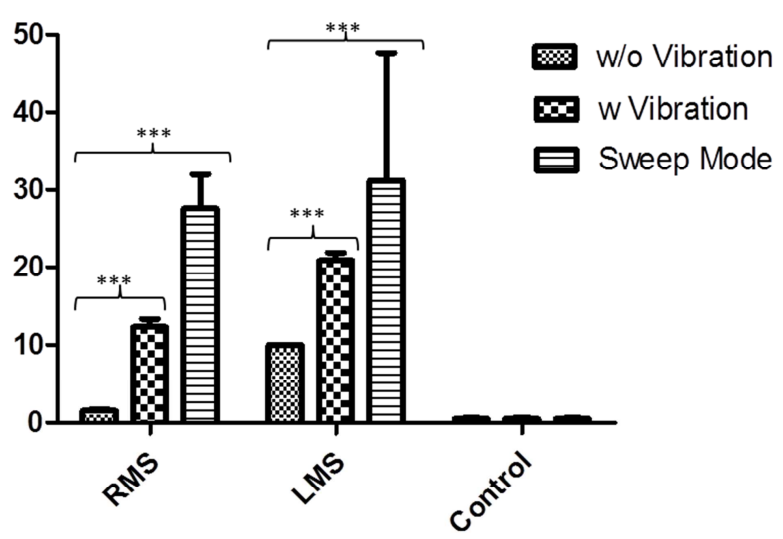

Figure 6 Impact of frequency sweep acoustic airflow on the intra-sinus drug deposition (in $\mathrm{mg} / \mathrm{L}$ ) in comparison with the impact of vibrating airflow supplied by commercial medical nebulizing devices; DTF and PARI SINUS respectively $(\mathrm{n}=6$, mean $\pm \mathrm{SEM}, * *(\mathrm{P}<0.01), * * *(\mathrm{P}<0.001))$.

\section{Discussion}

Numerical analysis of cranial images of the human plastinated cast acquired using the CTscanner returned the theoretical resonance frequency values of the maxillary sinuses of the nasal cast (referring to the Helmholtz resonator theory and the limitation of approximating the ostium to a cylinder and the MS to a sphere). Knowing that the size and geometrical dimensions of the human plastinated cast are reproduced in the nasal replica (12), we obtained the theoretical resonance frequencies of the left and right maxillary sinuses of the replica in order to compare them with the experimental results obtained in the aerosol drug deposition studies; we thus related the maximal aerosol deposition to the frequency of the superimposed 
acoustic airflow and verified its value with the numerically obtained value. Results showed that the resonance frequency of the right maxillary sinus, calculated using the Helmholtz resonator theory, is equal to $177 \mathrm{~Hz} \pm 10 \mathrm{~Hz}$, different from the resonance frequency of the left maxillary sinus which was found to be equal to $336 \pm 15 \mathrm{~Hz}$. To this day, commercial medical nebulizing systems are characterized by a fixed frequency acoustic airflow. Owing to the difference in resonance frequencies of each of the MS of the nasal replica, we assume that, in order to obtain the optimum aerosol deposition into each of the MS, we should use different medical nebulizing systems for each one. Depending on the severity of the illness of patients with CRS, the ostium is either completely or partially obstructed (17). This is also the case of patients who have undergone FESS and require after surgery therapy. Hence, to ensure the maximal drug deposition into the maxillary sinuses for each and every patient, a nebulizing device characterized by a specific frequency acoustic airflow has to be used.

The current study simulates reality. Although we used a decongested model of a healthy volunteer, differences in anatomy of its maxillary sinuses and ostia provide a simplified example of what happens in real life with CRS patients throughout the progression of their disease and/or with CRS patients after undergoing FESS and requiring further treatment. Relying on the results obtained in one of our previous studies (17), specific geometry of an ostium requires specific acoustic airflow characterized by a frequency that falls in the range of its resonance frequency spectrum.

Studies on the effect of application of acoustic airflow on intra-sinus drug deposition started in the last century (25). Later on, several studies were performed on the effectiveness of superposition of acoustic airflow in human cadavers and nasal casts $(26,27)$. These studies have been continued, and the results demonstrating the efficiency of application of an acoustic 
airflow on the aerosolized drug deposition into MS have been published. Among previous studies, a preliminary study of the aerosolized drug delivery to the paranasal sinuses performed by Moeller et al. on three healthy volunteers showed that $4.2 \pm 0.3 \%$ of total aerosol deposition deposited in the nose penetrated the sinuses under the effect of a pulsating acoustic airflow (characterized by a pressure wave of $45 \mathrm{~Hz}$ frequency); the deposition was below $1 \%$ without pulsation (28). Another study by Moeller et al., where 99mTc-DTPA pulsating aerosols were applied to eleven CRS patients without nasal polyps before and after surgery and in eleven healthy volunteers, showed that $4.8 \pm 2.2 \%$ of the administered aerosol could penetrate the maxillary sinus cavities of CRS patients prior to FESS, $8.2 \pm 3.8 \%$ of CRS patients after FESS and $9.7 \pm 25 \%$ of healthy volunteers. Nebulization experiments have been performed under the effect of $25 \mathrm{~Hz}$ acoustic airflow (27). A similar study investigated the impact of $100 \mathrm{~Hz}$ acoustic airflow on the gentamicin deposition into the maxillary sinus cavities of the human plastinated cast and demonstrated a 2-3 fold increase in the intra-sinus drug deposition when compared with the nebulization procedures without the superposition of acoustic airflow (10). It is worth noting that the description of volunteers was narrowed to sick versus healthy and the size and dimensions of maxillary sinuses and their ostia were not measured. The major aim of these studies was to highlight the impact of acoustic airflow on the enhanced intra-sinus drug deposition. Nevertheless, the degree of enhancement of the deposition versus the severity of obstruction of the ostia of CRS patients wasn't studied. In our study, we aimed at relating the degree of intra-sinus drug deposition to the frequency of the acoustic airflow and to the resonance frequency of the maxillary sinuses under study. 
Impact of fixed frequency acoustic airflow on intra-sinus aerosol deposition

We aimed at demonstrating that the amount of intra-sinus aerosol deposition varies with the frequency of the acoustic airflow and this explains our choice of nine frequency values. We wanted to have a wider range of frequency values to compare their effect on aerosol deposition. At the same time, we wanted to verify that the frequency of the acoustic airflow responsible for maximal aerosol deposition falls in the range of the calculated resonance spectrum of the MS according to the Helmholtz theory.

To study the $\mathrm{NaF}$ deposition under the effect of fixed frequency acoustic airflow nine frequency values $(50,100,150,200,300,400,500,600,700$ and $800 \mathrm{~Hz})$ were tested, and demonstrated a high aerosol deposition into the RMS under the effect of $150 \mathrm{~Hz}, 200 \mathrm{~Hz}, 300$ $\mathrm{Hz}$, and $400 \mathrm{~Hz}$ acoustic airflow. The optimal deposition was achieved at $150 \mathrm{~Hz}, 200 \mathrm{~Hz}$ and $300 \mathrm{~Hz}$. Referring to our hypothesis that the optimal aerosol deposition to the maxillary sinuses is attained under the effect of acoustic airflow characterized by a frequency value close or equal to the resonance frequency of each of the maxillary sinuses, the resonance frequency of the RMS should fall in the $150 \mathrm{~Hz}-400 \mathrm{~Hz}$ spectrum; upon the corresponding numerical analysis, the resonance frequency of the right maxillary sinus was calculated to be equal to $177 \pm 10 \mathrm{~Hz}$, which supports our initial hypothesis. With respect to the NaF collected from the LMS, a high aerosol deposition was recorded for the $150 \mathrm{~Hz}, 200 \mathrm{~Hz}, 300 \mathrm{~Hz}$, and $400 \mathrm{~Hz}$ acoustic airflow as in the case of aerosol deposition into the RMS. However, the quantity of aerosol deposition into LMS is always higher than the one in RMS due to the difference in morphology of the ostia of the LMS and RMS of the nasal replica (diameter of the LMS ostium is three times higher than that of the RMS) as previously described (12). The calculated resonance frequency of the LMS is equal to $336 \pm 15 \mathrm{~Hz}$. 
Theoretically calculated resonance frequency values of each of the maxillary sinuses of the nasal replica are in good agreement with the experimental fixed frequency values characterizing the acoustic airflow that resulted in maximal aerosol deposition into each of the MS.

Impact of sweep frequency acoustic airflow on intra-sinus aerosol deposition

$\mathrm{NaF}$ deposition into the maxillary sinuses using the frequency sweep acoustic airflow was tested using three frequency ranges, selected based on the deposition results obtained in experiments with fixed frequency acoustic airflow. Results demonstrated that $100-500 \mathrm{~Hz}$ frequency sweep acoustic airflow resulted in better $\mathrm{NaF}$ deposition into the maxillary sinuses of the nasal replica. It was observed that enhanced and statistically significant aerosol deposition was achieved in both maxillary sinuses using the same sweep mode, when compared with the aerosol deposition in the absence of acoustic airflow, indicating that the resonance frequency of each MS falls in the selected sweep range. These results open a way to new studies to be performed in the future testing different sweep frequency ranges of acoustic airflow to obtain a precise conclusion regarding the reasons behind the enhanced intra-sinus drug penetration.

Frequency sweep mode is characterized by a sweep cycle. We aimed at testing several sweep cycles to determine whether the duration of a cycle has an influence on the intra-sinus aerosol deposition. For the three sweep cycles chosen $(0.3 \mathrm{~s}, 3 \mathrm{~s}$, and $30 \mathrm{~s})$, results clearly demonstrated that the shorter the cycle, the better the deposition. Sweep cycle of $0.3 \mathrm{~s}$ resulted in a statistically significant $\mathrm{NaF}$ deposition into both maxillary sinuses when compared with the aerosol deposition in the absence of acoustic airflow. The $0.3 \mathrm{~s}$ cycle represents a $3 \mathrm{~Hz}$ signal, so we assume that the faster the superposition of one signal over another, the better the 
deposition. Difference between the results of $0.3 \mathrm{~s}, 3 \mathrm{~s}$ and $30 \mathrm{~s}$ cycles shows that the system is very sensitive to frequency modulation.

Effect of intensity of the frequency sweep acoustic airflow on intra-sinus aerosol deposition was also tested. However, only two intensity levels were tested: "high intensity" (128 dB) versus "low intensity" (120 dB). Intensity level of the acoustic airflow produced by the DTF nebulizing system was measured and found equal to $128 \mathrm{~dB}$. The two tested intensity levels are considered relatively high in acoustics; however, the terms "high intensity" and "low intensity" were selected to differentiate between these two values. No statistically significant difference in $\mathrm{NaF}$ collected from the maxillary sinuses under the effect of both intensities was observed. In this case, we cannot certainly say that the intensity of the acoustic airflow has no effect on the aerosol penetration because of the small range of the intensity tested. However we assume that at certain intensity level, i.e. a saturation point is reached resulting in a comparable aerosol deposition under the effect of different intensity levels. This gives rise to future studies for testing different intensity levels and their effect on nebulized drug deposition.

The final part of the study involved the use of gentamicin as a marker, and was performed to verify the benefits of the tested acoustic airflow obtained using NaF. The obtained results demonstrated the efficiency of the sweep acoustic airflow in enhancing the intra-sinus drug deposition to both sinuses simultaneously; thus providing a consistency with the results obtained using $\mathrm{NaF}$ as a marker. Comparing these results with the deposition results obtained using the acoustic airflow provided by the PARI Sinus and DTF nebulizing systems, the amount of gentamicin deposited in both the right and left maxillary sinuses was observed to be higher under the effect of the frequency sweep acoustic airflow. 
Hence, in the light of results obtained in our study, the frequency sweep acoustic airflow characterized by a very short sweep cycle provides a considerable solution for the treatment of CRS patients as it encompasses frequency values among which the resonance frequency of the MS of patients might fall. Moreover, in cases where the maxillary sinuses are partially filled with fluid and where the level of this fluid (and therefore the resonance frequency) varies during the healing process, the frequency sweep may also be an effective solution. However, to be able to draw more conclusions, further studies on our nasal replica and clinical trials thereafter have to be performed. Moreover, it is important to notice that our study focused only on the maxillary sinuses, but additional nasal cavities are involved in CRS. Therefore, further studies should be performed to improve our understanding of the effect of acoustic airflow in paranasal sinuses including frontal sinus and ethmoidal sinuses. 


\section{Conclusion}

For better targeting of maxillary sinuses characterized by ostia of different anatomy and geometry, nebulization characterized by an acoustic airflow of specific frequency close to the resonance frequency of each of the maxillary sinuses under treatment should be used. We have demonstrated that each of the maxillary sinuses of our nasal replica (LMS and RMS have different geometry of their ostia) requested a specific frequency acoustic airflow for an enhanced and significant aerosol deposition. Using a frequency sweep acoustic airflow encompassing a certain range of frequencies we were able to achieve an optimal drug deposition into both MS of our model. Frequency sweep mode itself is not enough; it should also be characterized by a sweep cycle of short duration; the shorter, the better. Therefore, for better targeting of maxillary sinuses of different degree of obstruction, a frequency sweep acoustic airflow could be superimposed on the nebulized drug ensuring better treatment. 
References

1. Cain RB, Lal D. Update on the management of chronic rhinosinusitis. Infect Drug Resist. 2013 Jan 23;6:1-14.

2. Dykewicz MS, Hamilos DL. Rhinitis and sinusitis. J Allergy Clin Immunol. 2010 Feb;125(2 Suppl 2):S103-15.

3. Tarhan E, Coskun M, Cakmak O, Çelik H, Cankurtaran M. Acoustic rhinometry in humans: accuracy of nasal passage area estimates, and ability to quantify paranasal sinus volume and ostium size. J Appl Physiol. 2005 Aug 1;99(2):616-23.

4. Fokkens WJ, Lund VJ, Mullol J, Bachert C, Alobid I, Baroody F, et al. European Position Paper on Rhinosinusitis and Nasal Polyps 2012. Rhinol Suppl. 2012 Mar;(23):3 p preceding table of contents, 1-298.

5. Fokkens W, Lund V, Mullol J, European Position Paper on Rhinosinusitis and Nasal Polyps group. European position paper on rhinosinusitis and nasal polyps 2007. Rhinol Suppl. 2007;(20):1-136.

6. Laube BL, Janssens HM, de Jongh FHC, Devadason SG, Dhand R, Diot P, et al. What the pulmonary specialist should know about the new inhalation therapies. Eur Respir J. 2011 Jun;37(6):1308-31.

7. De Monte M, Scruignec J, Dubus JC, Chaumuzeau JP, Dautzenberg B, Dessanges JF, et al. N.U.A.G.E.S: a survey of nebulisation practice in France with regard to ERS guidelines. Respir Med. 2007 Dec;101(12):2561-5.

8. Prulière-Escabasse V, Michel J, Percodani J, Serrano E, Gilain L, Crampette L, et al. Consensus document for prescription of nebulization in rhinology. Eur Ann Otorhinolaryngol Head Neck Dis. 2014 Dec;131(6):371-4.

9. Bhattacharyya N, Grebner J, Martinson NG. Recurrent Acute Rhinosinusitis: Epidemiology and Health Care Cost Burden. Otolaryngol--Head Neck Surg Off J Am Acad OtolaryngolHead Neck Surg. 2011 Oct 25.

10. Durand M, Pourchez J, Aubert G, Le Guellec S, Navarro L, Forest V, et al. Impact of acoustic airflow nebulization on intrasinus drug deposition of a human plastinated nasal cast: new insights into the mechanisms involved. Int J Pharm. 2011 Dec 12;421(1):63-71.

11. Durand M, Le Guellec S, Pourchez J, Dubois F, Aubert G, Chantrel G, et al. Sonic aerosol therapy to target maxillary sinuses. Eur Ann Otorhinolaryngol Head Neck Dis. 2012 Oct;129(5):244-50.

12. Leclerc L, Pourchez J, Aubert G, Leguellec S, Vecellio L, Cottier M, et al. Impact of airborne particle size, acoustic airflow and breathing pattern on delivery of nebulized 
antibiotic into the maxillary sinuses using a realistic human nasal replica. Pharm Res. 2014 Sep;31(9):2335-43.

13. Leclerc L, Pourchez J, Prevot N, Vecellio L, Le Guellec S, Cottier M, et al. Assessing sinus aerosol deposition: Benefits of SPECT-CT imaging. Int J Pharm. 2014 Jan;462:135-141.

14. Möller W, Schuschnig U, Khadem Saba G, Meyer G, Junge-Hülsing B, Keller M, et al. Pulsating aerosols for drug delivery to the sinuses in healthy volunteers. Otolaryngol--Head Neck Surg Off J Am Acad Otolaryngol-Head Neck Surg. 2010 Mar;142(3):382-8.

15. Möller W, Lübbers C, Münzing W, Canis M. Pulsating airflow and drug delivery to paranasal sinuses. Curr Opin Otolaryngol Head Neck Surg. 2011 Feb;19(1):48-53.

16. Mainz JG, Schädlich K, Schien C, Michl R, Schelhorn-Neise P, Koitschev A, et al. Sinonasal inhalation of tobramycin vibrating aerosol in cystic fibrosis patients with upper airway Pseudomonas aeruginosa colonization: results of a randomized, double-blind, placebo-controlled pilot study. Drug Des Devel Ther. 2014;8:209-17.

17. Leclerc L, El Merhie A, Navarro L, Prevot N, Durand M, Pourchez J. Impact of acoustic airflow on intrasinus drug deposition: new insights into the vibrating mode and the optimal acoustic frequency to enhance the delivery of nebulized antibiotic. Int J Pharm. 2015.

18. Durand M, Pourchez J, Louis B, Pouget JF, Isabey D, Coste A, et al. Plastinated nasal model: a new concept of anatomically realistic cast. Rhinology. 2011 Mar;49(1):30-6.

19. Möller W, Schuschnig U, Bartenstein P, Meyer G, Häussinger K, Schmid O, et al. Drug delivery to paranasal sinuses using pulsating aerosols. J Aerosol Med Pulm Drug Deliv. 2014 Aug;27(4):255-63.

20. Guellec SL, Pennec DL, Gatier S, Leclerc L, Cabrera M, Pourchez J, et al. Validation of Anatomical Models to Study Aerosol Deposition in Human Nasal Cavities. Pharm Res. 2014 Jan 1;31(1):228-37.

21. Wang C, Lou H, Wang X, Wang Y, Fan E, Li Y, et al. Effect of budesonide transnasal nebulization in patients with eosinophilic chronic rhinosinusitis with nasal polyps. J Allergy Clin Immunol. 2015 Apr 1;135(4):922-9.e6.

22. Reychler G, Colbrant C, Huart C, Guellec SL, Vecellio L, Rombaux P. Comparison of three modalities of corticosteroids administration in chronic rhinosinusitis. Eur Respir J. 2014 Sep 1;44(Suppl 58):P959.

23. Durand M, Pourchez J, Aubert G, Le Guellec S, Navarro L, Forest V, et al. Impact of acoustic airflow nebulization on intrasinus drug deposition of a human plastinated nasal cast: new insights into the mechanisms involved. Int J Pharm. 2011 Dec 12;421(1):63-71.

24. Hyo N, Takano H, Hyo Y. Particle deposition efficiency of therapeutic aerosols in the human maxillary sinus. Rhinology. 1989 Mar;27(1):17-26. 
25. Guillerm R, Badre R, Flottes L, Riu R, and Rey A: "Nouveau procede assurant la penetration des aerosols dans les sinus. [A new method of aerosol penetration into the sinuses.]." Presse Med. 1959;67:1097-1098.

26. Moeller W, Schuschnig U, Meyer G, Häussinger K, Keller M, Junge-Hülsing B, et al. Ventilation and aerosolized drug delivery to the paranasal sinuses using pulsating airflow a preliminary study. Rhinology. 2009 Dec;47(4):405-12.

27. Sato Y, Hyo N, Sato M, Takano H, and Okuda S: "Intranasal distribution of aerosols with or without vibration." Z Erkr Atmungsorgane. 1981;157:276-280.

28. Möller W, Schuschnig U, Celik G, Münzing W, Bartenstein P, Häussinger K, et al. Topical Drug Delivery in Chronic Rhinosinusitis Patients before and after Sinus Surgery Using Pulsating Aerosols. PLoS ONE. 2013 Sep 11;8(9):e74991. 